\title{
Massey Cancer Center
}

National Cancer Institute

\section{Source}

National Cancer Institute. Massey Cancer Center. NCI Thesaurus. Code C39448.

The Massey Cancer Center serves Virginia and the nation as a comprehensive center of excellence in cancer research, prevention and control, patient care, and education. The Center's goals are to make important discoveries about cancer, and to translate these discoveries rapidly into better prevention, detection, treatment, and control of cancer to enhance the quality of life of all individuals affected by cancer. It is affiliated with the Virg inia Commonwealth University and has been funded by an NCl Cancer Center Support Grant since 1975. 